\title{
The prediction of the turned machining induced residual stresses in Ti6Al4V: A Critical Surface Integrity Descriptor
}

\author{
Gary Styger $^{1 *}$, Rudolph F Laubscher ${ }^{1}$ \\ ${ }^{1}$ University of Johannesburg, Department of Mechanical Engineering Sciences, Corner of Auckland \\ Park and Kingsway, South Africa
}

\begin{abstract}
The surface integrity of a turned machined surface is an essential indicator of a component's fatigue and corrosion performance. A critical descriptor of this property is the residual stress, both on the surface and subsurface of a part. However, experimental determination of vital surface integrity parameters such as surface roughness, hardness, affected microstructure, and residual stresses are costly, time-consuming, and involve the part's destruction. Therefore, predicting these parameters, such as residual stress versus depth, would be of great value and could aid in the correct machining parameters (cutting speed, feed rate, edge tool radius, rake angle, coolant) for the desired part performance being selected. A study was undertaken to determine the influence of a worn tool and multiple cuts on a wide range of cutting speeds on residual stresses induced by machining an outside-turned bar of Ti6Al4V titanium alloy. Thus, a project was begun to build a non-linear dynamic finite element model to predict the residual stresses thus developed due to the machining manufacturing process.
\end{abstract}

\section{Introduction}

The aeronautical and medical industries are primarily users of titanium due to their corrosion resistance and strength to weight ratio. Grade 5 titanium is a standard titanium alloy in use in the industry. The manufacturing of titanium components is often challenging. High-speed machining of titanium alloys remains a challenge for the suppliers, customers, machine-tool designers, and cutting insert/tool manufacturers. Metal cutting causes extensive plastic deformations and high temperatures. These coupled mechanical and thermal effects introduce surface changes in the component. This process may affect the workpiece's material properties and residual stress state at the surface and near-surface. The higher cutting speeds found in high-speed machining may result in a generation of tensile residual stresses - the low thermal conductivity of titanium, high-temperature toughness, and chemical reactivity of titanium exacerbate this problem. The machining-induced residual stresses typically are evaluated with non-contact probing techniques such as $\mathrm{x}$-ray diffraction. Numerical predictions of the cutting process may significantly reduce the effort to quantify the residual stress state of a machined surface. Recently, Ozel et al. [1] showed that "useful" results could

\footnotetext{
* Corresponding author: garystyger@gmail.com
} 
be possible by finite element modelling (FEA) of the residual stress state and comparison to experimental data. They also concluded that the tool micro-geometry influences the residual stress state. This paper reports on the current work, evaluating the geometry change due to the "worn tool" predicted from simulations. Multiple cutting passes were then simulated, considering the updated "worn tool" geometry. The predicted residual surface stresses induced by each "cutting pass" were compared to data from X-ray Diffraction (XRD) results extracted from a 3D oblique outside turned sample.

Outeiro et al. [2] suggest a procedure for extracting the "numerically-predicted" nearsurface machining-induced residual stresses with XRD to measure the residual stresses in the sample. The procedure is as follows:

The predicted residual stresses should be extracted from the FE model far enough away from the chip formation zone, suggesting $1.5 \mathrm{~mm}$.

The mean value of the predicted surface residual stress should be evaluated over a finite volume of the work material. The minimal spatial resolution that the X-ray diffraction can achieve is approximately $1 \mathrm{~mm}$ in the direction normal to the X-ray beam and a sub-surface $10-20 \mu \mathrm{m}$ depth in the direction of the X-ray beam.

The predicted residual stresses should be extracted from the FE model after multiple simulated cutting passes.

The tool wear should be monitored during the machining tests, and it must be considered when modelling the residual stresses. This work predicted the wear of the insert with the use of the FEA model.

Besides the above conditions, it must also be noted that FE models predict only the macro (type-1) residual stresses. While a non-destructive technique such as X-ray diffraction measures both macro (type-1) and micro (type-2) residual stresses, the correlation between the predicted and measured residual stress results is challenging and remains a topic of intense research.

\section{Experimental work}

A $75 \mathrm{~mm}$ Grade 5 round bar was turned in a lathe at different cutting speeds $(30,100$ and $200 \mathrm{~m} / \mathrm{min})$, feed $(0.2 \mathrm{~mm} / \mathrm{rev})$ and depth of cut $(1 \mathrm{~mm})$ under both coolant and dry conditions. A new SANDVIKTM CNMA 120408 H1P (uncoated carbide) insert was used per cutting speed. The geometry of the insert consisted of a negative rake angle of 5 degrees, a relief angle of 5 degrees and a tool nose radius of $0.8 \mathrm{~mm}$. A conventional emulsified mineral oil-based flood cooling system was utilised.

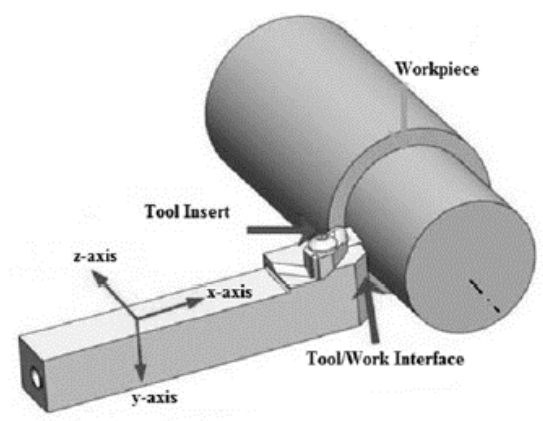

Fig. 1. Turning machining setup [3]. 
Light optical microscopy with an Olympus BX-51M Optical Microscope with a digital camera was utilised to evaluate the chip morphology. The chip segmentation ratio was measured for each of the cutting speeds. The chip segmentation ratio $\left(\mathrm{G}_{\mathrm{S}}\right)$ is given by:

$$
G_{S}=\left(h_{\max }-h_{\min )} h_{\max }\right.
$$

Where $\mathrm{h}_{\max }$ is the maximum chip thickness, and $\mathrm{h}_{\min }$ is the minimum chip thickness. $\mathrm{G}_{\mathrm{s}}=$ 1 implies a completely segmented or discontinuous chip. Gs $=0$ implies a fully continuous chip without any segmentation occurring.

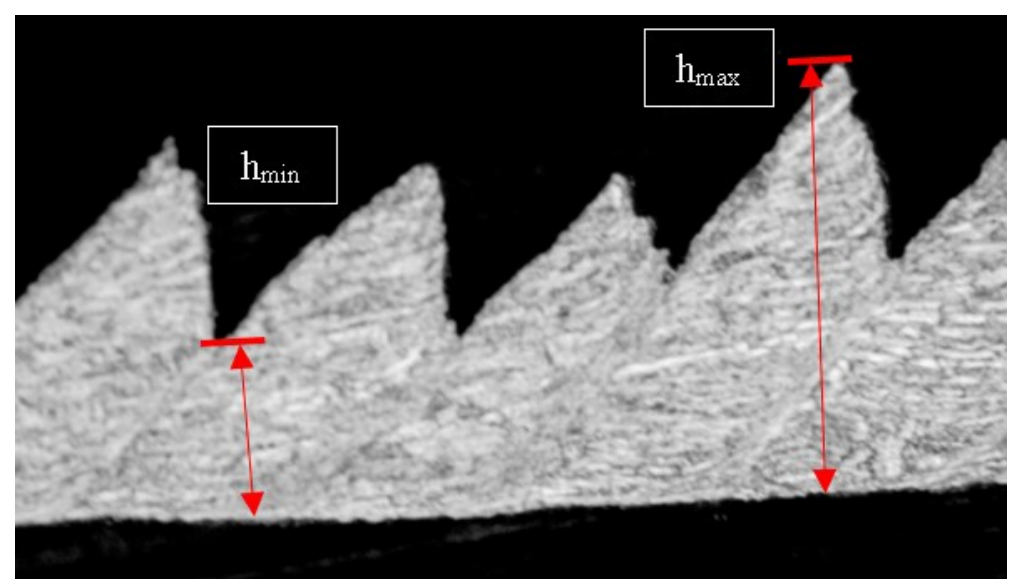

Fig. 2. Distances are required to predict the chip segmentation ratio.

The width of the flank land between the crater and cutting edge (KF) and the distance from the edge to the back crater contour (KB) was measured from the light optical microscopy images, using MIPAR ${ }^{\mathrm{TM}}$ Version 3.4.2 [4].
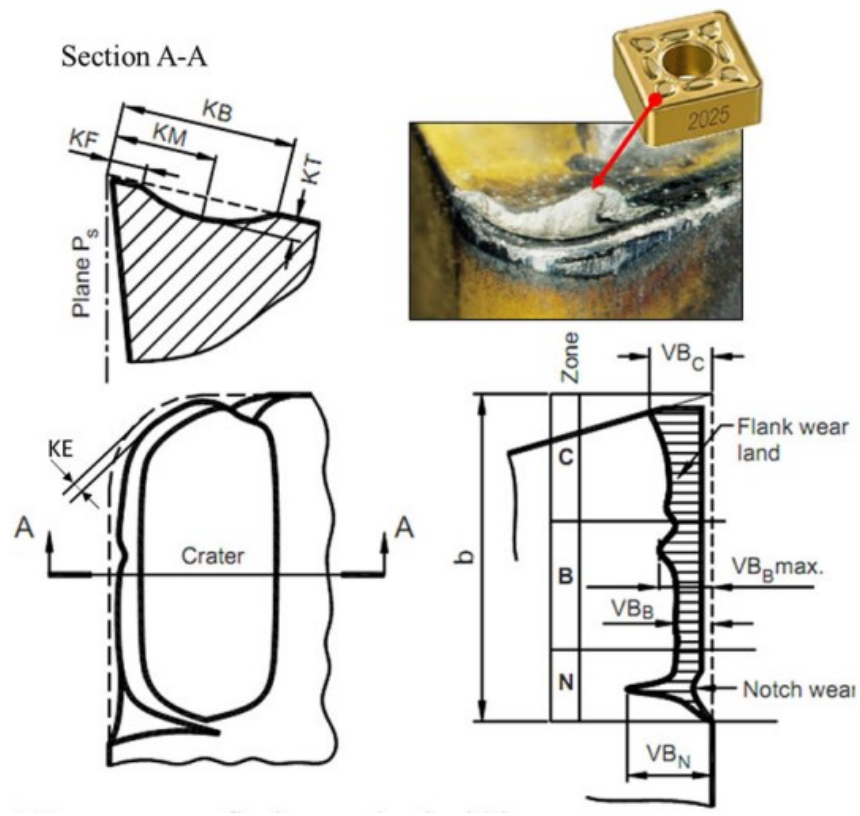

Fig. 3. Typical tool inserts wear patterns [5]. 


\section{Numerical work}

Thirdwave Systems AdvantEdge ${ }^{\mathrm{TM}}$ Version 7.8 is a finite element analysis software dedicated to certain $2 \mathrm{D}$ and $3 \mathrm{D}$ machining operations. It helps predict cutting forces, temperatures in the workpiece and the tool, and tool wear and deflection. The solution algorithm is based on a dynamic explicit Lagrangian coupled thermo-mechanical formulation [6]. The model is built by selecting the type of machining operation such as turning, broaching, sawing, or milling. The main interest of the current work is orthogonal turning. The required process parameters are feed rate, depth of cut, length of the cut, cutting speed and initial temperature of the workpiece. Cutting tool geometry, including tool tip radius, rake and relief angle, can all be individually set. The material properties of the tool and the workpiece also need to be defined-AdvantEdge ships with an extensive materials library for both the workpiece and tool materials. Various "thermoviscoplastic" material models are available for use. The included material libraries to be unsuitable in the prediction of the machining-induced residual stresses [7].

In this study, the "Power-Law" phenomenological model material model for Ti6Al4V was used as implemented by Laubscher et al. [7]. Default element sizes from the software were used in this study. The software implements continuous adaptive remeshing which is used to overcome severely distorted elements at the cutting interface during the simulation. The outside turning process was modelled as a $2 \mathrm{D}$ plane strain orthogonal model for this work. Further functionality is available via FORTRAN user-subroutines for the material models.

\section{Tool}

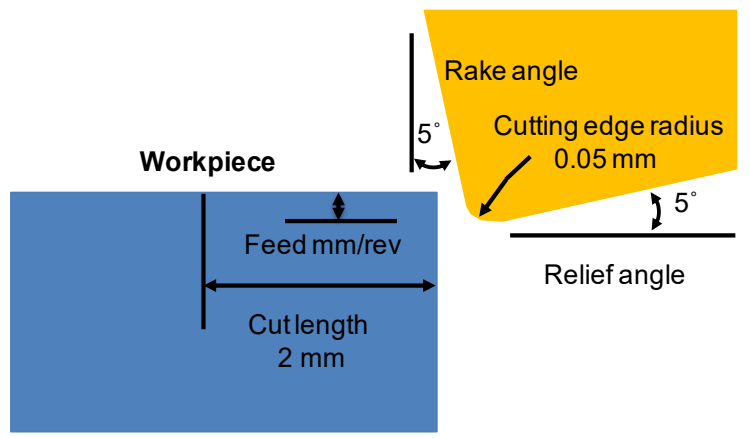

Fig. 4. Setup of the simulation model [7].

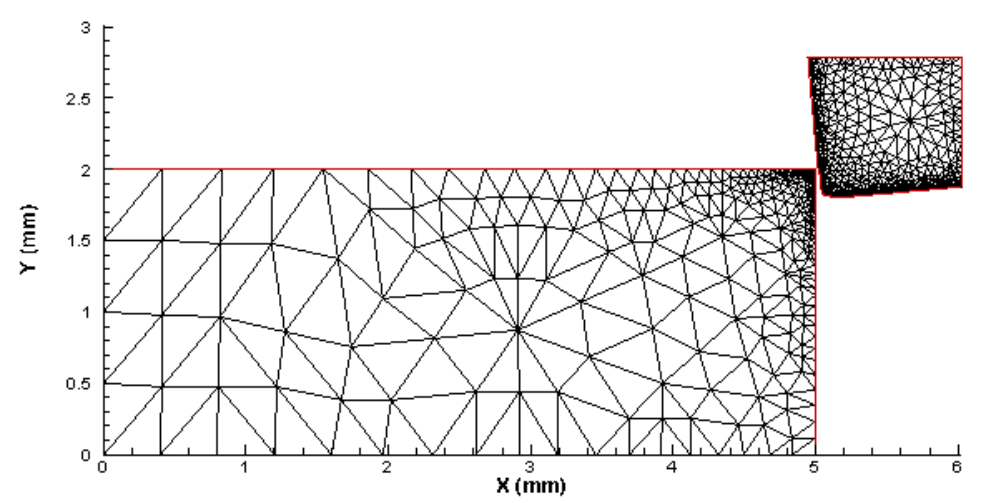

Fig. 5. Initial mesh [8].

A cut depth of $1 \mathrm{~mm}$ and a range of different cutting speeds $(30,100$ and $200 \mathrm{~m} / \mathrm{min}$ ) were evaluated. The feed rate was $0.2 \mathrm{~mm} / \mathrm{rev}$. Conventional flood cooling is modelled with 
an assumed general convection coefficient of $100 \mathrm{~W} / \mathrm{m}^{\wedge} 2 . \mathrm{K}$ [7]. Dry cooling is modelled with an assumed general convection coefficient of $20 \mathrm{~W} / \mathrm{m}^{\wedge} 2$. K. Simulations were run with and without coolant. The Coulomb friction model is implemented in the software [8]. The coefficient of friction of 0.5 was assumed for all simulations.

Prediction of tool wear is available within AdvantEdge. Various models of wear are available. Fortran user-defined wear models can be implemented if standard models do not meet user requirements. Mishra et al. [9] conducted experimental and numerical work to determine the coefficients required for Usai's wear model for dry machining of Ti6Al4V to predict the rake 'crater wear' and 'flank wear'. This wear model and the determined coefficients were implemented in the software's 'wear' simulations for all cutting speeds. The tool's nodal positions are updated based on the "wear rate" from the Usai wear model's calculation.

$$
\left.d w d t=K e_{(}-\alpha /(T+273.15)\right) p \mathrm{~V}
$$

Where $\mathrm{dw} / \mathrm{dt}=$ wear rate $($ Volume loss per unit area per unit time), $\mathrm{K}=8.13 \mathrm{e}-8(1 / \mathrm{Pa})-$ Usai's wear constant, $\alpha=244.63$ - Usai's wear constant, $\mathrm{V}=$ sliding velocity (length / time).

The user must input the 'cutting time' over which the 'wear' of the tool should be considered. The total cutting length for each cutting speed was $30 \mathrm{~mm}$ from the outside turning machining experiments. Therefore, the cutting time was calculated for the numerical model for a cutting length of $30 \mathrm{~mm}$ based on each cutting speed. Figure 4 shows an example of the resultant "worn tool" overlaid with the new tool. The "worn" tool geometry was exported from the software and then re-imported into the software for the " $11^{\text {st }}$ cut" and " $2^{\text {nd }}$ cut" simulations to predict the residual stresses of each pass.

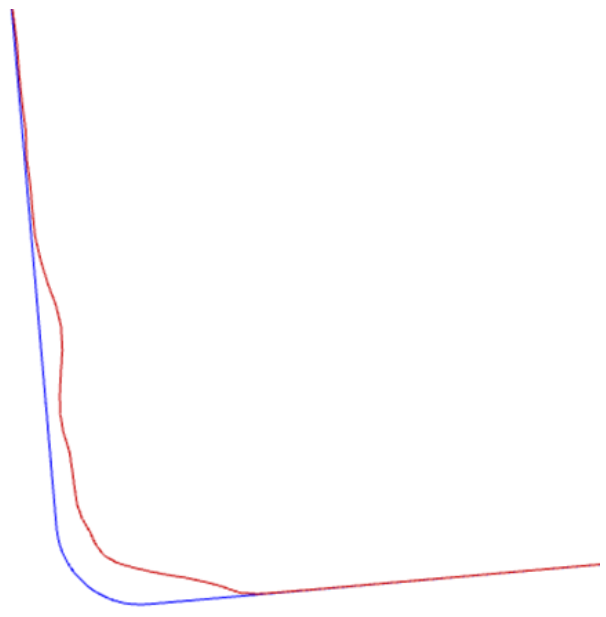

Fig. 6. New tool (blue) and worn tool (red) overlayed

Residual stress can be evaluated after a single or secondary cut by numerical removal of the chip and tool after the prescribed cut length within the software. A procedure allowing for thermo-mechanical relaxation is then conducted. Vibrations are damped out from the dynamic explicit solution, and heat is allowed to dissipate sufficiently for the workpiece to attain the initial prescribed room temperature. Both first and second cut simulations were conducted to evaluate the effect of the machining-induced residual stresses. 


\section{Results}

The results of the chip morphology, tool wear, and XRD residual stress measurements and the numerically predicted residual stresses will be discussed in the following sections.

\subsection{Chip morphology}

Laubscher et al. [6] describe that titanium alloys develop segmented chips, even at low cutting speeds. The chip segmentation for each of the cutting speeds as well as the coolant and dry conditions for the experimental work, is herein described. The table below indicates the chips are segmented $(\mathrm{GS}<1)$ for all cutting speeds. The predicted results indicate a minor deviation of $2 \%$ from the Ti6Al4V outside turned bar, running at a cutting speed of 100 $\mathrm{m} / \mathrm{min}$ without coolant, for the first cut, compared to the measured results. The most significant deviation of $34 \%$ was found for the predicted cutting speed of $30 \mathrm{~m} / \mathrm{min}$ without coolant for the first cut compared to the measured results. The predicted results for the first and second cuts show a reasonable correlation with the measured results, considering that a $3 \mathrm{D}$ oblique outside turned sample is compared to a $2 \mathrm{D}$ plane strain orthogonal numerical model for predictions.

Table 1. Results of the chip segmentation ratio for the measured and predicted chips.

\begin{tabular}{|c|c|c|c|c|c|c|}
\hline $\begin{array}{c}\text { Cutting } \\
\text { Speed } \\
\text { (m/min) }\end{array}$ & $\begin{array}{c}\text { Cool- } \\
\text { ant/Dry }\end{array}$ & $\begin{array}{c}\text { Measured } \\
\text { chip seg- } \\
\text { mentation } \\
\text { Ratio }\end{array}$ & $\begin{array}{c}\text { Numerical } \\
\text { chip segmen- } \\
\text { tation Ratio - } \\
\text { 1st cut }\end{array}$ & $\begin{array}{c}\text { Numerical } \\
\text { chip segmen- } \\
\text { tation Ratio - } \\
\text { 2nd cut }\end{array}$ & $\begin{array}{c}\text { Devia- } \\
\text { tion - 1st } \\
\text { cut }\end{array}$ & $\begin{array}{c}\text { Devia- } \\
\text { tion - } \\
\text { 2nd cut }\end{array}$ \\
\hline 30 & Coolant & 0.50 & 0.61 & 0.52 & $22 \%$ & $4 \%$ \\
\hline 30 & Dry & 0.47 & 0.63 & 0.61 & $34 \%$ & $29 \%$ \\
\hline 100 & Coolant & 0.55 & 0.52 & 0.50 & $-4 \%$ & $-8 \%$ \\
\hline 100 & Dry & 0.63 & 0.64 & 0.58 & $2 \%$ & $-7 \%$ \\
\hline 200 & Coolant & 0.73 & 0.58 & 0.52 & $-21 \%$ & $-29 \%$ \\
\hline 200 & Dry & 0.55 & 0.64 & 0.58 & $17 \%$ & $7 \%$ \\
\hline
\end{tabular}




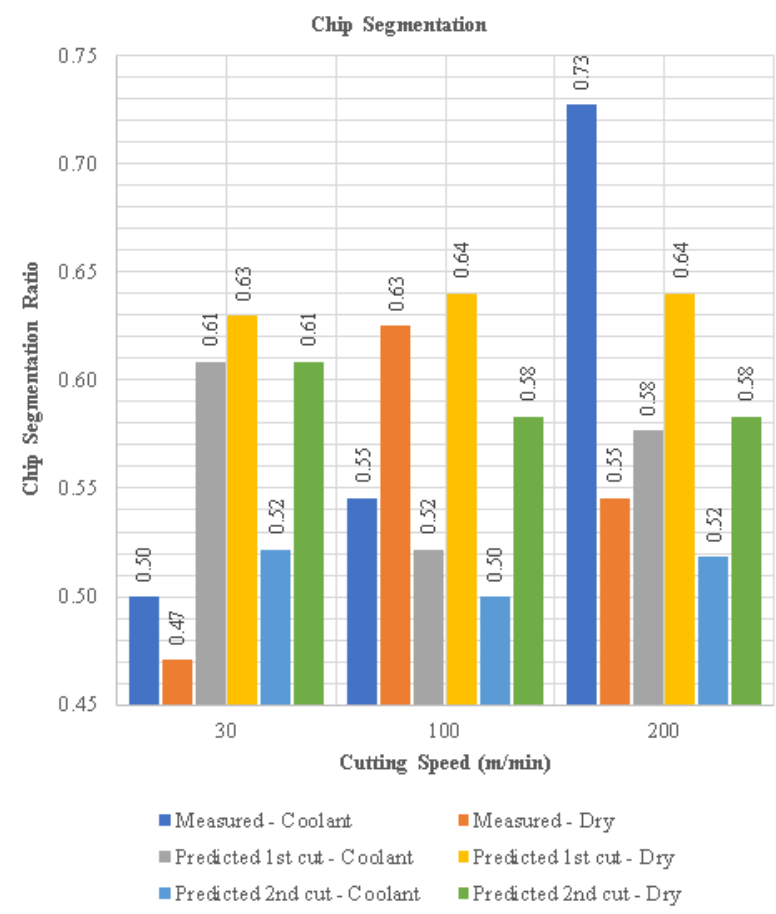

Fig. 7. Results plot of the chip segmentation.

The numerical results predict "segmented chips".

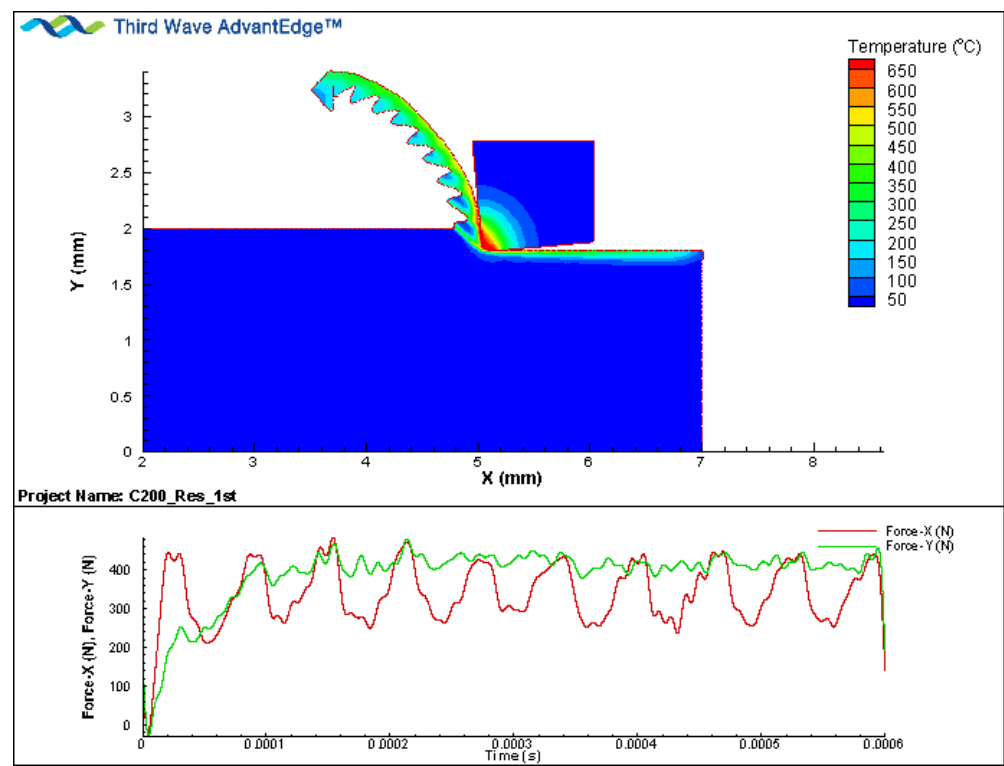

Fig. 8. The numerical model predicts segmented chips as seen in this contour plot of the temperatures and the "cyclic" nature of the cutting forces. 


\subsection{Worn tool measurements}

The worn tool measurements for each cutting speed and the coolant and dry conditions for the experimental work are described herein. The table below indicates the KB and KF distances (described above) for all cutting speeds. Outeiro et al. [2] found that for predicting orthogonal machining of AISI 316L stainless steel, after a second cut and the inclusion of the worn tool's geometry, increased compressive surface residual stresses along the length of the cut. The predicted results indicate the minor deviation of $6 \%$ from the Ti6Al4V outside turned bar, running at $30 \mathrm{~m} / \mathrm{min}$ without coolant, for the first cut compared to the measured results. The most significant deviation of $65 \%$ was found for the predicted cutting speed of $30 \mathrm{~m} / \mathrm{min}$ with coolant, for the first cut, compared to the measured results. The predicted results for the first and second cuts show a reasonable correlation with the measured results, considering that a $3 \mathrm{D}$ oblique outside turned sample is compared to a $2 \mathrm{D}$ plane strain orthogonal numerical model for predictions.

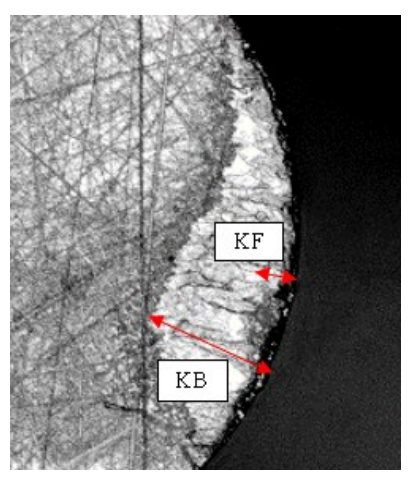

Fig. 9. Image of the tool wear showing the "built-up" edge of titanium in the worn crater.

Table 2. Results of the tool wear distances for KB and KF for the measured and predicted tools.

\begin{tabular}{|c|c|c|c|c|c|c|c|}
\hline $\begin{array}{c}\text { Cutting } \\
\text { Speed } \\
(\mathbf{m} / \mathbf{m i n})\end{array}$ & $\begin{array}{c}\text { Cool- } \\
\text { ant/Dry }\end{array}$ & $\begin{array}{c}\text { Measured } \\
-\mathbf{K F} \\
\mathbf{( m m})\end{array}$ & $\begin{array}{c}\text { Measured } \\
-\mathbf{K B}(\mathbf{m m})\end{array}$ & $\begin{array}{c}\text { Numeri- } \\
\mathbf{c a l}-\mathbf{K F} \\
\mathbf{( m m})\end{array}$ & $\begin{array}{c}\text { Numeri- } \\
\mathbf{c a l}-\mathbf{K B} \\
\mathbf{( m m})\end{array}$ & $\begin{array}{c}\text { Devia- } \\
\text { tions - } \\
\text { KF }\end{array}$ & $\begin{array}{c}\text { Devia- } \\
\text { tions - } \\
\text { KB }\end{array}$ \\
\hline 30 & Coolant & 0.02 & 0.14 & 0.03 & 0.17 & $\mathbf{6 5 \%}$ & $21 \%$ \\
\hline 30 & Dry & 0.05 & 0.20 & 0.05 & 0.22 & $\mathbf{- 6 \%}$ & $12 \%$ \\
\hline 100 & Coolant & 0.04 & 0.17 & 0.06 & 0.20 & $38 \%$ & $15 \%$ \\
\hline 100 & Dry & 0.03 & 0.14 & 0.04 & 0.15 & $30 \%$ & $10 \%$ \\
\hline 200 & Coolant & 0.03 & 0.18 & 0.03 & 0.20 & $10 \%$ & $8 \%$ \\
\hline 200 & Dry & 0.03 & 0.21 & 0.04 & 0.20 & $27 \%$ & $-7 \%$ \\
\hline
\end{tabular}




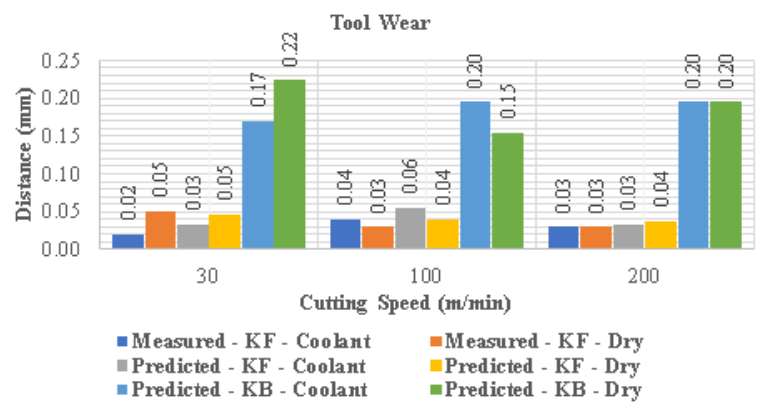

Fig. 10. Results plot of the tool wear.

\subsection{Residual stress measurements}

Surface residual stresses were evaluated by the Nelson Mandela University (eNtsa) using non-contact X-ray diffraction. The surface residual stress measurements were measured with a ProtoTM i-XRD combo with a copper $x$-ray source, using a $2 \mathrm{~mm}$ round aperture. These experimental results were compared with those of the numerical work discussed in this paper.

Table 3. XRD measurement parameters.

\begin{tabular}{|c|c|c|c|c|c|c|}
\hline $\begin{array}{c}\text { Voltage } \\
(\mathrm{kV})\end{array}$ & $\begin{array}{c}\text { Current } \\
(\mathrm{mA})\end{array}$ & Filters & $\begin{array}{l}\text { Bragg } \\
\text { angle }\end{array}$ & $\begin{array}{l}\text { Exposure } \\
\text { time (sec) }\end{array}$ & $\begin{array}{c}\text { No. } \\
\text { Exposures/angle }\end{array}$ & $\begin{array}{l}\text { Psi } \\
\text { osc }\end{array}$ \\
\hline 20 & 4 & $\mathrm{Ni}$ & $\begin{array}{c}139.69^{\circ} \\
\text { on } 213 \mathrm{hk}\end{array}$ & 3 & 12 & $3^{\circ}$ \\
\hline
\end{tabular}

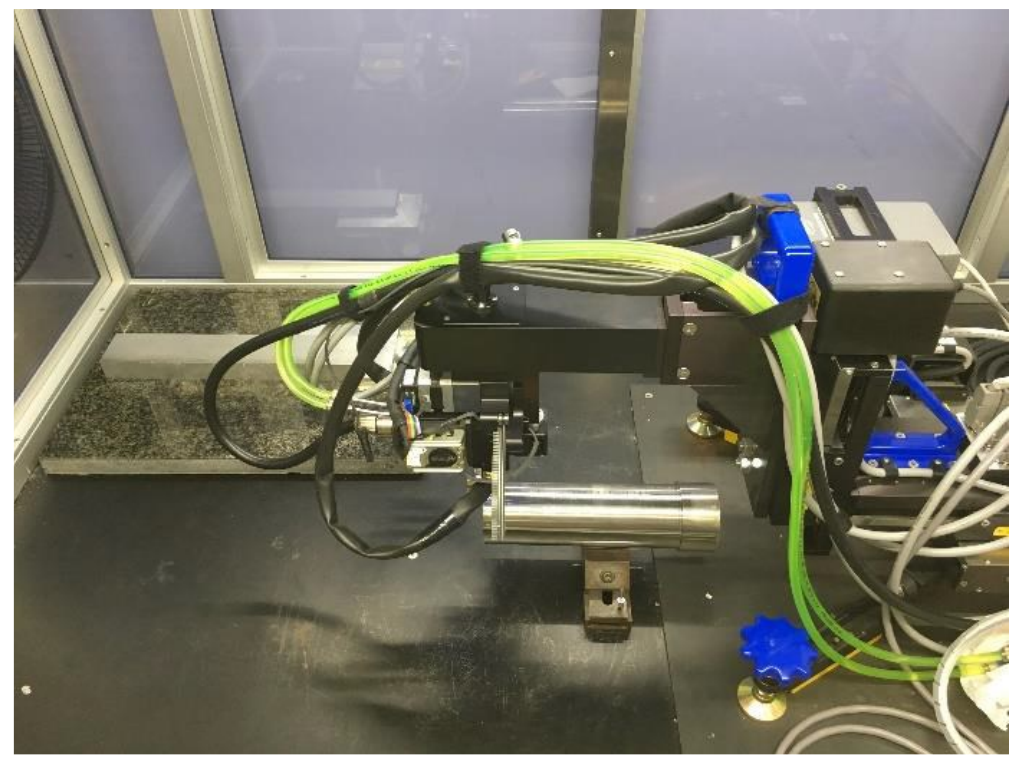

Fig. 11. Experimental setup for the XRD residual stress measurements. 


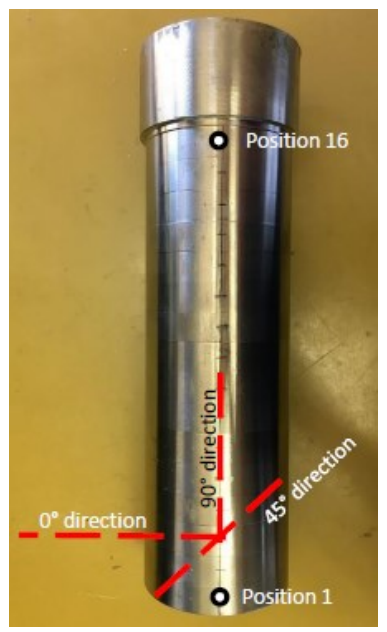

Fig. 12. Direction of the direct stress components.

\section{Results}

This study's residual stress vs depth was extracted from the centre $(1 \mathrm{~mm}$ from the chip formation zone) of the total cutting length of $2 \mathrm{~mm}$. This extracted distance is a deviation from the recommended procedure as described by Outeiro [2]. The predicted surface residual stresses were averaged over 18 microns below the surface to compare the XRD measured and predicted residual stresses. These residual stresses were only extracted for a single position along the cutting length. Hence no averaging of the results occurred in the cutting direction. Ozel et al. [1] found the surface residual stresses compressive for Ti6Al4V at different cutting speeds. The predicted results indicate a minor deviation of $11 \%$ from the Ti6Al4V outside turned bar, running at $200 \mathrm{~m} / \mathrm{min}$ with coolant, for the second cut compared to the measured results. The most significant deviation of $56 \%$ was found for the predicted cutting speed of $100 \mathrm{~m} / \mathrm{min}$ without coolant for the second cut compared to the measured results. The predicted results for the first and second cuts show a reasonable correlation with the measured results, considering that a $3 \mathrm{D}$ oblique outside turned sample is compared to a 2D plane strain orthogonal numerical model for predictions.

Table 4. Results of the measured and predicted residual stresses.

\begin{tabular}{|c|c|c|c|c|c|c|}
\hline $\begin{array}{c}\text { Cutting } \\
\text { speed } \\
\mathbf{( m / m i n )}\end{array}$ & $\begin{array}{c}\text { Cool- } \\
\text { ant/Dry }\end{array}$ & $\begin{array}{c}\text { Measured } \\
\text { stress (MPa) }\end{array}$ & $\begin{array}{c}\text { Stress for } \\
\text { the 1 } \\
\text { st cut } \\
\mathbf{M P a})\end{array}$ & $\begin{array}{c}\text { Stress for } \\
\text { the second } \\
\text { cut (MPa) }\end{array}$ & $\begin{array}{c}\text { Deviation } \\
\text { for the 1st } \\
\text { cut (\%) }\end{array}$ & $\begin{array}{c}\text { Deviation } \\
\text { for the 2nd } \\
\text { cut (\%) }\end{array}$ \\
\hline 30 & Coolant & -400 & -357 & -456 & $-11 \%$ & $14 \%$ \\
\hline 30 & Dry & -290 & -432 & -338 & $49 \%$ & $17 \%$ \\
\hline 100 & Coolant & -327 & -278 & -247 & $-15 \%$ & $-25 \%$ \\
\hline 100 & Dry & -253 & -350 & -395 & $38 \%$ & $\mathbf{5 6 \%}$ \\
\hline 200 & Coolant & -363 & -212 & -402 & $-42 \%$ & $\mathbf{1 1 \%}$ \\
\hline 200 & Dry & -310 & -208 & -395 & $-33 \%$ & $28 \%$ \\
\hline
\end{tabular}




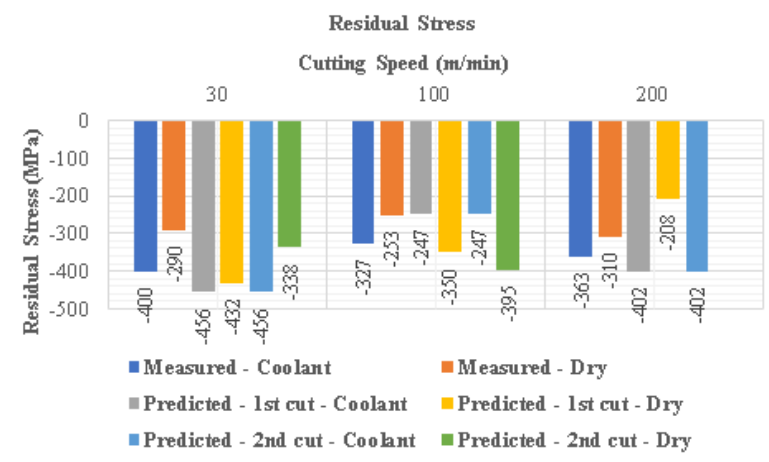

Fig. 13. "Measured" and "Predicted" near-surface residual stresses.

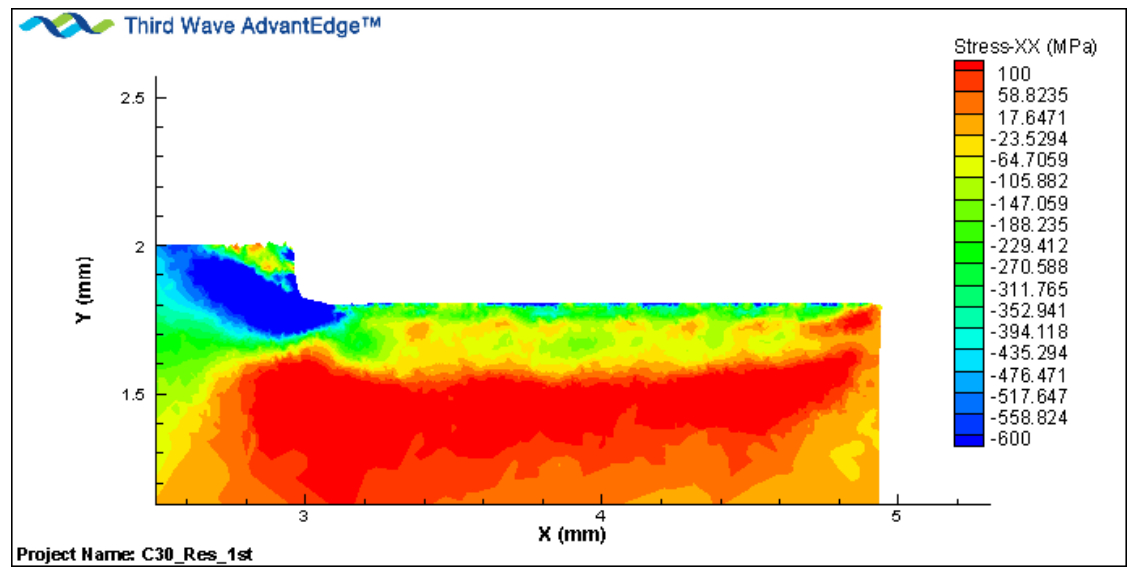

Fig. 14. Contour plot of the residual stresses, in the cutting direction for the cutting speed of 30 $\mathrm{m} / \mathrm{min}$ with coolant.

\section{Conclusions}

This paper presents a numerical simulation of outside turning of Grade 5 titanium alloy, considering tool wear and multiple cuts, to predict residual surface stresses. The non-linear and dynamic FEA results are compared and validated against experimental work. A dedicated phenomenological material model had to be used to correctly capture the observed experimental behaviour of the machining-induced residual stresses. This constitutive model is based on experimental work conducted and published data for Grade 5 [7]. Reasonable agreement between experimental work and the simulation results as far as chip morphology and tool wear is achieved. The simulation presents a good approximation of the surface residual stresses at several cutting speeds. It correctly presents a fully compressive residual stress field. The simulation correctly captures that the maximum compressive residual stress is located a finite distance below the surface. It does, however, not accurately capture the cutting speed sensitivity as observed in the literature. The difficulty in predicting the changes in the residual stresses with different cutting speeds are believed to be linked to the thermal modelling component of the simulation that assumes a simple Coulomb friction model with a single value for the coefficient of friction across the insert-to-workpiece interface. A constant overall heat transfer coefficient and an assumed heat transfer over the toolworkpiece interface without considering the effects of temperature changes. A more generalpurpose non-linear finite element code where the user controls the thermal aspects (heat 
generation and dissipation) of the modelling will be required to investigate this further. The modelling procedure, as recommended by Outeiro [2] as followed in this paper, demonstrates the relevance of considering tool wear and multiple cuts before extracting the residual stresses from the numerical model.

\section{References}

1. T. Ozel, D. Ulutan, Predication of machining-induced residual stresses in turning of titanium and nickel based alloys with experiments and finite element simulations, CIRP Annals, 61, Issue 1, 547-550 (2012)

2. J. Outeiro, K. Ee, O. Dillon, P. Wanigarathne, I. Jawahir, Some Observations on Comparing the Modelled and Measured Residual Stresses on the Machined Surface Induced by Orthogonal Cutting of AISI 316L Steel, Proceedings of the 9th CIRP International Workshop on Modeling of Machining Operations, 11-12 May, Bled, Slovenia, 475-481 (2006)

3. G. Styger, R.F. Laubscher, G. Oosthuizen, Effect of Constitutive Modeling During Finite Element Analysis of Machining-induced Residual Stresses in Ti6Al4 V. Procedia CIRP. 13, 292-431 (2014)

4. J. Sosa, D. Huber, B. Welk, H. Fraser, Development and application of MIPAR ${ }^{\text {TM: }}$ a novel software package for two- and three-dimensional microstructural characterisation, Integrating Materials, 3, 123-140 (2014)

5. L. Čerče, F. Pušavec, and J. Kopač, A New Approach to Spatial Tool Wear Analysis and Monitoring, Journal of Mechanical Engineering 61, Issue 9, 489-497 (2015)

6. T. D. Marusich and M. Ortiz, Modelling and Simulation of High-Speed Machining, International Journal of Numerical Methods in Engineering, 38, 3675-3694 (1995)

7. R. Laubscher, G. Styger, and G. Oosthuizen, A numerical analysis of machininginduced residual stresses of grade 5 titanium alloy, R \& D J. South Afr. Inst. Mech. Eng. 30, 39-46 (2014)

8. AdvantEdge ${ }^{\mathrm{TM}}$ USER MANUAL, 1-340 (2020)

9. S. K. Mishra, S. Ghosh, S. Aravindan, Temporal and spatial crater wear prediction of WC/Co tools during dry turning of Ti6Al4V alloy, Wear, 448-449, 203-229 (2020) 